\title{
Physical activity of subjects aged 50-64 years involved in the European Prospective Investigation into Cancer and Nutrition (EPIC)
}

\author{
M Haftenberger ${ }^{1, *}$, A Schuit ${ }^{2}, \mathrm{~W} \mathrm{Tormo}^{3}, \mathrm{H}_{\text {Boeing }}{ }^{1}, \mathrm{~N}$ Wareham ${ }^{4}$, \\ HB Bueno-de-Mesquita ${ }^{2}$, M Kumle $^{5}, \mathrm{~A} \mathrm{Hjartåker}^{6}, \mathrm{MD} \mathrm{Chirlaque}^{3}, \mathrm{E} \mathrm{Ardanaz}^{7}, \mathrm{CAndren}^{8}$, \\ B Lindah ${ }^{9}$, PHM Peeters ${ }^{10}$, NE Allen ${ }^{11}$, K Overvad ${ }^{12}$, A Tjønneland $^{13}$, \\ F Clavel-Chapelon ${ }^{14}$, J Linseisen ${ }^{15}$, MM Bergmann ', A Trichopoulou 16', P Lagiou ${ }^{16}$, \\ S Salvini ${ }^{17}$, S Panico ${ }^{18}$, E Riboli $^{19}$, P Ferrari $^{19}$ and N Slimani ${ }^{19}$ \\ 'German Institute of Human Nutrition, Department of Epidemiology, Arthur Scheunert Allee 114-1 16, D-14558 \\ Potsdam-Rehbrücke, Germany: ${ }^{2}$ Centre of Chronic Diseases Epidemiology, National Institute of Public Health and the \\ Environment, Bilthoven, The Netherlands: ${ }^{3}$ Council for Health and Social Affairs of Murcia, Spain: ${ }^{4}$ Department of \\ Public Health and Primary Care, School of Clinical Medicine, University of Cambridge, UK: Institute of Community \\ Medicine, University of Tromsø, Norway: ${ }^{6}$ Section for Medical Statistics, University of Oslo, Norway: ${ }^{7}$ Institute of \\ Public Health, Regional Government of Navarra, Spain: ${ }^{8}$ Department of Medicine, Lund University, Malmö University \\ Hospital, Sweden: ${ }^{9}$ Department of Public Health and Clinical Medicine, Umeå University, Sweden: ${ }^{10}$ Julius Center \\ for General Practice and Patient Oriented Research, University of Utrecht, The Netherlands: " $C a n c e r$ Research UK, \\ Epidemiology Unit, University of Oxford, UK: ${ }^{12}$ Department of Epidemiology and Social Medicine, University of \\ Aarhus, Denmark: ${ }^{13}$ Danish Cancer Society, Copenhagen, Denmark: ${ }^{14}$ INSERM, E3N-EPIC Group, Institute \\ Gustave Roussy, Villejuif, France: ${ }^{15}$ Division of Clinical Epidemiology, German Cancer Research Centre, Heidelberg, \\ Germany: ${ }^{16}$ Department of Hygiene and Epidemiology, School of Medicine, University of Athens, Greece: \\ ${ }^{17}$ Molecular and Nutritional Epidemiology Unit, CSPO, Scientific Institute of Tuscany, Florence, Italy: ${ }^{18}$ Department \\ of Clinical and Experimental Medicine, Federico II University, Naples, Italy: ${ }^{19}$ International Agency for Cancer \\ Research, Lyon, France
}

\begin{abstract}
Objective: To describe physical activity of participants in the European Prospective Investigation into Cancer and Nutrition (EPIC).

Design: A cross-sectional analysis of baseline data of a European prospective cohort study.

Subjects: This analysis was restricted to participants in the age group 50-64 years, which was represented in all EPIC centres. It involved 236386 participants from 25 centres in nine countries. In each EPIC centre, physical activity was assessed by standardised and validated questions. Frequency distribution of type of professional activity and participation in non-professional activities, and age-adjusted means, medians and percentiles of time dedicated to non-professional activities are presented for men and women from each centre.

Results: Professional activity was most frequently classified as sedentary or standing in all centres. There was a wide variation regarding participation in different types of non-professional activities and time dedicated to these activities across EPIC centres. Over $80 \%$ of all EPIC participants engaged in walking, while less than $50 \%$ of the subjects participated in sport. Total time dedicated to recreational activities was highest among the Dutch participants and lowest among men from Malmö (Sweden) and women from Naples (Italy). In all centres, total time dedicated to recreational activity in the summer was higher than in the winter. Women from southern Europe spent the most time on housekeeping.

Conclusions: There is a considerable variation of physical activity across EPIC centres. This variation was especially evident for recreational activities in both men and women.
\end{abstract}

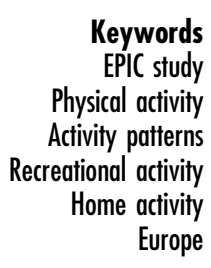

Physical activity plays an important role in the prevention of certain cancer types and other chronic diseases ${ }^{1}$. There is convincing evidence for a protective effect of physical activity on the risk of colon cancer, while no association has been observed between physical activity and the risk of rectal cancer ${ }^{2-4}$. Prospective cohort studies and casecontrol studies have also shown an inverse relationship between physical activity and the risk of breast ${ }^{2,3,5-9}$, 
uterine $^{2,3}$ and lung cancer ${ }^{2,10}$. Whether physical activity reduces the risk of prostate cancer is still unclear ${ }^{2,11,12}$. There are only a limited number of studies showing inconsistent results regarding the effect of physical activity on other cancer sites ${ }^{2}$.

Prospective studies are needed in order to establish further scientific evidence for the relation between physical activity and the risk of different cancer types and other chronic diseases. The European Prospective Investigation into Cancer and Nutrition (EPIC), which was established primarily to study the relationship between diet and other lifestyle factors and chronic diseases, particularly cancer, is a large-scale prospective multicentre cohort study. EPIC used standardised methods to assess physical activity at the baseline examination ${ }^{13}$. The high expected variation in both physical activity and disease risk within the EPIC study population makes this cohort particularly valuable for further studies of the relationship between physical activity and disease risk.

This paper describes the variation in physical activity for EPIC participants aged 50-64 years. It aims to describe both professional and non-professional activities, and the amount of time dedicated to non-professional activities by men and women from the different EPIC centres. The intention of this analysis is to identify the physical activity patterns of the different EPIC study populations rather than to rate the physical activity of subjects in terms of scores or classifications. Approaches to classifying EPIC participants according to their levels of total physical activity are currently under discussion and will be presented in the future.

\section{Methods}

\section{Subjects}

The EPIC study is a multi-centre prospective study involving 23 administrative study centres in 10 countries. Initially, the EPIC study was set up by study groups from France, Germany, Greece, Italy, Spain, The Netherlands and the UK; it was subsequently joined by already existing cohorts from Naples (Italy), Sweden, Denmark and Norway with a similar set of procedures and study variables. Over 500000 middle-aged men and women are involved in the EPIC study. The baseline data were collected between 1992 and 2000. The EPIC study populations were not intended to be representative of the general population. The choice of study populations was influenced largely by practical possibilities of obtaining adequate participation and ensuring long-term follow-up ${ }^{13}$. In France, Norway, Naples (Italy) and Utrecht (The Netherlands), only women were examined. The EPIC centre Bilthoven covers study populations from three Dutch towns: Amsterdam, Doetinchem and Maastricht. EPIC study populations were either population-based (Bilthoven, The Netherlands; Greece; Germany; Sweden; Denmark; Norway; part of the population from the UK,
Spain and Italy) or represented special groups - namely, participants in breast cancer screening programmes (Utrecht, The Netherlands; Florence, Italy), blood donors (Spain; Ragusa and Turin, Italy), teachers and school workers (France), employees (Turin, Italy), medical test users (Turin, Italy) and vegetarians, vegans and other health-conscious individuals recruited in collaboration with vegetarian societies and magazines (part of the population studied in the UK). Study populations, recruitment and characteristics of the populations are described in more detail elsewhere in this supplement ${ }^{14}$. The age range of participants varied between EPIC study centres. In order to reduce heterogeneity due to different age ranges between centres, the present analysis was restricted to 84515 men and 166065 women aged 50-64 years old. This age group was included in all study centres. This analysis did not include participants from Norway, since physical activity data from Norway were not comparable with data from the other centres.

\section{Assessment of physical activity}

In each centre, professional and non-professional physical activity was assessed as a part of the standardised lifestyle questionnaire ${ }^{13,14}$. The physical activity questions were part of the EPIC core protocol and are shown in Appendix A. In the different EPIC centres, the questions on physical activity were incorporated in face-to-face interviews or self-administered questionnaires. In the Malmö (Sweden) centre and the Italian centre of Naples, which joined EPIC after study inception, physical activity was inquired in a different way, but the data could subsequently be transformed into the EPIC core categories of physical activity (Appendix A). The physical activity questions being asked in the Umeå (Sweden) and Norway centres were different from the EPIC core questions and are not presented here.

The core question on actual professional activity was solicited in most EPIC centres. In the centres in France, Italy, the UK, Germany, The Netherlands, Greece and Sweden, employment status and type of physical activity at work were solicited. In the Danish centres, the question focused only on current type of work activity. Subjects of these centres who did not answer the question were categorised as non-working. In the Spanish centres, all participants were classified into one of the categories of work activity independent of employment status. Housekeeping activities were categorised as standing most of the time. Subjects were classified regarding physical activity at work as: non-worker, sedentary, standing, manual, heavy manual and unknown activity at work. Different questions were used in Norway, which was therefore not included in the analysis.

In the EPIC centres in France, Italy (except Naples), Spain, the UK, The Netherlands, Greece and Germany, which contributed to EPIC from the beginning, and in the Danish centres, non-professional physical activity was 
assessed by using the core questions regarding specific recreational physical activities, comprising cycling, walking, gardening and sports, and specific home activities, comprising housekeeping and home repair (do-it-yourself). Information on duration of recreational activities was obtained for both summer and winter seasons. This enables analyses of summer and winter differences in recreational activities in the different EPIC study populations. In the Italian centres, household activities were only solicited for women. In the Dutch centres, participants were also asked about the duration of home activities for both summer and winter seasons.

A study of the reproducibility and relative validity of a set of questions closely approximating the EPIC core questions for non-professional activity was performed in a sample of 126 men and women aged 20-70 years from The Netherlands. This study showed that these questions were inappropriate for estimating energy expenditure on an absolute level, but the reproducibility and relative validity of ranking the subjects were within acceptable ranges ${ }^{15}$.

In Naples (Italy), physical activity questions differed slightly from the EPIC core questions. Cycling was not queried as a separate activity, but included in the question on sports/exercise. Participants were asked about the duration of walking, gardening and sports/exercise referring to the entire year and not to summer and winter separately. An evaluation of the differences in these activities between the summer and winter was therefore not possible for the EPIC Naples centre.

In Malmö (Sweden), a variant of the Minnesota Leisure Time Physical Activity Questionnaire was used to assess leisure-time physical activity. This questionnaire asked about participation and duration (hours per week) of 16 recreational activities in all four seasons and included one open-ended question for additional activities (see Appendix B). Different activity items were regrouped according to the EPIC categories (walking, cycling, gardening and sports). The duration of each activity category was calculated and expressed as $\mathrm{h}_{\text {week }}{ }^{-1}$. For this centre, the mean duration of spring and summer activity represented the EPIC variable for duration of an activity in summer, while that of autumn and winter represented the EPIC variable of winter. In addition, a question was asked regarding housework in the Malmö questionnaire that was comparable with the EPIC core question. The question on climbing stairs did not match with the EPIC core question and home repair activity was not solicited by the Malmö physical activity questionnaire.

In the Italian centres, the duration of non-professional activities was solicited by means of various categories: 0 , less than 1, 1-2, 3-4, 5-6, 7-8, 9-10 and 11 or more $\mathrm{h}_{\text {week }}{ }^{-1}$ for recreational activity and home repair; and 0 , less than 1, 1-2, 3-4, 5-6 and 7 or more $\mathrm{hday}^{-1}$ for household activities. These categories were transformed to continuous values by using the mean of each category; for example, $1-2 \mathrm{~h}$ week $^{-1}$ was replaced by $1.5 \mathrm{~h}$ week $^{-1}$. The maximum category, e.g. 11 or more $\mathrm{h}_{\text {week }}{ }^{-1}$, was replaced by the sex-specific median value from the participants of the other centres with a duration of more than the penultimate category.

When all physical activity variables were missing, implying that subjects did not answer the physical activity questionnaire, the duration of an activity was set to missing. If at least one of the questions was answered, missing values for other activity items were converted to zero, assuming that the subject completed the questionnaire, but did not participate in that particular activity.

The duration of each separate physical activity was calculated as the mean time dedicated to each activity in summer and winter, expressed as h week ${ }^{-1}$. The duration of total recreational physical activity was calculated as the sum of time dedicated to each of the four leisure activities (walking, cycling, gardening and sports/exercise).

Data on physical activity were available for 77853 men and 158533 women aged 50-64 years. The proportion of missing values for the various physical activity items was generally lower than $10 \%$ in all centres except in Bilthoven (The Netherlands), where data on professional activity were missing for $21 \%$ of the men and $18 \%$ of the women; the general population of the UK, where data on professional activity were missing for $11 \%$ of the men and $14 \%$ of the women; and Asturias (Spain) where data on professional activity were missing for $18 \%$ of the men and $9 \%$ of the women. In Bilthoven (The Netherlands), the EPIC physical activity questionnaire was used only from the second year onwards, resulting in missing information for 1534 subjects aged 50-64 years who were recruited in the first study year.

\section{Statistical analyses}

For the present analysis, the administrative centres were regrouped into 27 EPIC study centres, as described elsewhere ${ }^{16}$. These centres generally refer to geographical regions, except for the centres in the UK, which refer either to a sample of the general population or to a sample of subjects with a health-conscious lifestyle. Since no comparable data for Norway were available, only 25 centres are described here.

Frequency distributions of type of professional activity and participation in non-professional activities are presented for men and women in each centre. For those subjects participating in the different non-professional activities, the mean and standard deviation, and the 10th, 50th (median) and 90th percentiles of the time dedicated to these activities are presented. These statistical measures were adjusted for age, using the residuals of linear regression with age as the independent variable and the duration of each activity as the dependent variable.

Seasonal variation of total duration in recreational activity was analysed by calculating the median difference of duration of total recreational activity in summertime 
minus wintertime and its 95\% confidence interval. Differences between physical activity in summer- and wintertime were assumed to be significant when zero was not included in the confidence interval.

\section{Results}

Table 1 shows the frequency distribution of type of professional activity in men and women from the different EPIC centres. Since the question on professional activity used in the centres from Spain deviated from that used in the remaining centres, professional activity data from these centres are described separately below. In the remaining centres, the proportion of non-workers varied from 15\% (Copenhagen, Denmark) to 43\% (Varese and Turin, Italy; Potsdam, Germany) in men and from 25\% (Umeå, Sweden) to $73 \%$ (Varese, Italy) in women. In all EPIC centres, a sedentary or standing professional activity was most common. There was a considerable variation in the proportion of subjects who did manual and heavy manual work across the centres. Relatively high proportions of participants with a manual or a heavy manual professional activity were observed in men and women from the centres of Greece, Umeå (Sweden) and Denmark, and in women from the centre of Utrecht (The Netherlands).

In the Spanish centres, where activity at work was asked about regardless of employment status, 26-36\% of men stated their activity as sedentary, $32-42 \%$ as standing, $11-28 \%$ manual and 3-9\% as heavy manual. Among the Spanish women, between $82 \%$ and $90 \%$ of the subjects did standing work.

Tables 2-5 show participation and time dedicated to recreational activities for men and women. Walking was the most common recreational activity in all EPIC centres. Participation in walking ranged from 68\% (Malmö, Sweden) to $98 \%$ (Potsdam, Germany) in men and from 27\% (Naples, Italy) to 99\% (Potsdam, Germany) in women.

Table 2 Walking in men and women aged 50-64 years in different European Prospective Investigation into Cancer and Nutrition (EPIC) centres: participation $(n, \%)$ and age-adjusted mean, standard deviation (SD), and 10th, 50th and 90th percentiles $\left(P_{10}, P_{50}\right.$ and $\left.P_{90}\right)$ of duration $\left(\mathrm{h} \mathrm{week}^{-1}\right)$

\begin{tabular}{|c|c|c|c|c|c|c|c|c|c|c|c|c|c|c|c|c|}
\hline \multirow[b]{3}{*}{ Country and centre } & \multicolumn{8}{|c|}{ Men } & \multicolumn{8}{|c|}{ Women } \\
\hline & \multirow[b]{2}{*}{$n^{\star}$} & \multicolumn{2}{|c|}{ Participation } & \multicolumn{5}{|c|}{$\begin{array}{c}\text { Duration } \\
(\mathrm{h} \text { week }\end{array}$} & \multirow[b]{2}{*}{$n^{\star}$} & \multicolumn{2}{|c|}{ Participation } & \multicolumn{5}{|c|}{$\begin{array}{c}\text { Duration } \\
\left(\mathrm{h} \text { week }^{-1}\right)\end{array}$} \\
\hline & & $n \dagger$ & $\%$ & Mean & $\mathrm{SD}$ & $P_{10}$ & $P_{50}$ & $P_{90}$ & & $n \dagger$ & $\%$ & Mean & $\mathrm{SD}$ & $P_{10}$ & $P_{50}$ & $P_{90}$ \\
\hline \multicolumn{17}{|l|}{ Greece } \\
\hline Greece & 3676 & 3505 & 95.4 & 7.0 & 5.1 & 2.1 & 6.2 & 13.6 & 5993 & 5773 & 96.3 & 6.0 & 3.9 & 1.9 & 5.2 & 10.5 \\
\hline \multicolumn{17}{|l|}{ Spain } \\
\hline Granada & 904 & 856 & 94.7 & 9.4 & 9.0 & 1.8 & 7.0 & 20.2 & 2597 & 2464 & 94.9 & 6.5 & 4.6 & 1.9 & 5.9 & 13.8 \\
\hline Murcia & 1291 & 1085 & 84.0 & 8.9 & 8.1 & 2.2 & 7.0 & 17.6 & 2331 & 2069 & 88.8 & 6.8 & 5.8 & 2.0 & 6.7 & 13.8 \\
\hline Navarra & 1917 & 1635 & 85.3 & 9.1 & 7.7 & 1.8 & 7.3 & 18.3 & 1745 & 1546 & 88.6 & 7.8 & 5.2 & 2.0 & 6.9 & 14.1 \\
\hline San Sebastian & 2147 & 1936 & 90.2 & 10.6 & 8.1 & 2.7 & 8.1 & 20.6 & 1639 & 1486 & 90.7 & 9.4 & 6.6 & 2.7 & 7.3 & 17.3 \\
\hline Asturias & 1360 & 1327 & 97.6 & 11.3 & 7.6 & 3.5 & 9.1 & 21.1 & 1962 & 1900 & 96.8 & 9.6 & 5.7 & 3.1 & 7.3 & 15.0 \\
\hline \multicolumn{17}{|l|}{ Italy } \\
\hline Ragusa & 1064 & 975 & 91.6 & 5.5 & 4.7 & 0.9 & 3.8 & 14.6 & 940 & 864 & 91.9 & 3.9 & 3.5 & 0.6 & 2.8 & 8.3 \\
\hline Naplesł & - & - & - & - & - & - & - & - & 2306 & 617 & 26.8 & 2.2 & 2.3 & 0.5 & 1.6 & 5.5 \\
\hline Florence & 1702 & 1639 & 96.3 & 5.1 & 4.2 & 1.0 & 3.8 & 12.0 & 6530 & 6367 & 97.5 & 5.2 & 4.0 & 1.2 & 3.7 & 11.8 \\
\hline Turin & 2774 & 9164 & 97.1 & 5.6 & 4.2 & 1.2 & 4.3 & 12.5 & 2307 & 2270 & 98.4 & 5.6 & 4.3 & 1.3 & 4.4 & 12.4 \\
\hline Varese & 1585 & 1507 & 95.1 & 4.3 & 4.0 & 0.6 & 2.9 & 10.2 & 4470 & 4236 & 94.8 & 3.9 & 3.7 & 0.7 & 2.6 & 9.4 \\
\hline \multicolumn{17}{|l|}{ France } \\
\hline South coast $\ddagger$ & - & - & - & - & - & - & - & - & 5717 & 5395 & 94.4 & 7.0 & 7.7 & 1.5 & 4.8 & 14.0 \\
\hline South $\ddagger$ & - & - & - & - & - & - & - & - & 10124 & 9581 & 94.6 & 6.7 & 7.3 & 1.4 & 4.6 & 13.6 \\
\hline North-west & - & - & - & - & - & - & - & - & 6067 & 5765 & 95.0 & 6.7 & 7.4 & 1.5 & 4.7 & 13.7 \\
\hline North-east & - & - & - & - & - & - & - & - & 16736 & 15924 & 95.2 & 6.9 & 7.4 & 1.4 & 4.8 & 14.2 \\
\hline \multicolumn{17}{|l|}{ Germany } \\
\hline Heidelberg & 7235 & 7103 & 98.2 & 7.0 & 6.1 & 1.6 & 5.3 & 14.3 & 6442 & 6352 & 98.6 & 7.3 & 6.0 & 1.8 & 5.8 & 14.2 \\
\hline Potsdam & 6137 & 6068 & 98.9 & 8.7 & 6.8 & 2.1 & 6.9 & 17.9 & 7417 & 7354 & 99.2 & 9.2 & 6.6 & 2.5 & 7.4 & 17.6 \\
\hline \multicolumn{17}{|l|}{ The Netherlands } \\
\hline Bilthoven & 2510 & 2394 & 95.4 & 13.6 & 13.6 & 2.4 & 8.8 & 34.7 & 2669 & 2553 & 95.7 & 12.9 & 13.0 & 2.2 & 8.2 & 33.1 \\
\hline Utrecht & - & - & - & - & - & - & - & - & 13384 & 13134 & 98.1 & 7.9 & 8.8 & 1.4 & 5.0 & 18.0 \\
\hline \multicolumn{17}{|l|}{ United Kingdom } \\
\hline General population & 6992 & 6476 & 92.6 & 9.3 & 10.9 & 1.6 & 5.8 & 20.3 & 9894 & 9288 & 93.8 & 8.4 & 9.0 & 1.9 & 5.9 & 17.3 \\
\hline 'Health-conscious' & 2476 & 2402 & 97.0 & 6.5 & 6.2 & 1.4 & 4.8 & 13.4 & 8510 & 8270 & 97.2 & 7.4 & 6.5 & 1.9 & 5.8 & 14.7 \\
\hline \multicolumn{17}{|l|}{ Denmark } \\
\hline Copenhagen & 18477 & 16988 & 91.9 & 4.7 & 5.6 & 1.0 & 3.0 & 9.8 & 20856 & 19567 & 93.8 & 4.7 & 4.9 & 1.1 & 3.2 & 9.8 \\
\hline Aarhus & 8318 & 7503 & 90.2 & 3.8 & 3.5 & 1.0 & 2.7 & 7.8 & 8592 & 8061 & 93.8 & 4.1 & 3.5 & 1.1 & 3.1 & 8.1 \\
\hline \multicolumn{17}{|l|}{ Sweden } \\
\hline Malmö & 7288 & 4939 & 67.8 & 3.0 & 3.1 & 0.5 & 2.1 & 6.4 & 9325 & 6812 & 73.1 & 3.5 & 3.1 & 0.8 & 2.8 & 7.0 \\
\hline
\end{tabular}

* Number of respondents.

† Number of active participants.

$\ddagger$ Only women. 
Among subjects who participated in walking, the median

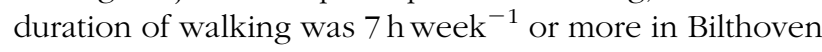
(The Netherlands), Potsdam (Germany) and most centres from Spain. In contrast, the median duration of walking was less then $3.5 \mathrm{hweek}^{-1}$ in men and women from Varese and Naples (Italy), women from Ragusa (Italy) and in the centres from Sweden and Denmark. The participation in and time dedicated to cycling were the highest in the centres from The Netherlands. Participation varied from $69 \%$ to $87 \%$ and the median of duration of cycling varied from 3.1 to $3.6 \mathrm{hweek}^{-1}$. A high participation in cycling was also observed in the centres of Copenhagen (Denmark) and Heidelberg (Germany). Relatively low proportions of the study populations from Greece and Spain cycled (2-23\%), although these participants spent a considerable time cycling. The proportions of subjects who participated in gardening varied from 22\% (San Sebastian, Spain) to 89\% (general population, UK) in men and from $13 \%$ (Naples, Italy) to $87 \%$ ('health-conscious' group, UK) in women. Although the proportion of participants who gardened was relatively low in the Spanish centres, these participants spent a considerable time gardening; median time spent gardening was $8.1 \mathrm{~h} \mathrm{week}^{-1}$ in men from Asturias (Spain). In the 'health-conscious' group (UK), with the highest participation in gardening among the EPIC centres, the median time dedicated to gardening was $3 \mathrm{~h} \mathrm{week}^{-1}$. In the EPIC cohort as a whole, less than $50 \%$ of the subjects participated in sports/exercise. However, there was a wide variation between centres, ranging from 15\% (Granada, Spain) to $55 \%$ (Turin, Italy) in men and from $7 \%$ (Naples, Italy) to $63 \%$ (South coast of France) in women. The median time dedicated to sports and exercise of active participants varied from 1 to $3 \mathrm{hweek}^{-1}$ in men and women. In the French centres having the highest participation in sports/exercise (53-67\%), the median duration of these activities was $2 \mathrm{~h}$ week ${ }^{-1}$.

The median of total duration of recreational activity, shown in Table 6, varied for men between $5.0 \mathrm{hweek}^{-1}$ (Malmö, Sweden) and $15.5 \mathrm{hweek}^{-1}$ (Bilthoven, The

Table 3 Cycling in men and women aged 50-64 years in different European Prospective Investigation into Cancer and Nutrition (EPIC) centres: participation $(n, \%)$ and age-adjusted mean, standard deviation (SD), and 10th, 50th and 90th percentiles (P $P_{10}$, $P_{50}$ and $\left.P_{90}\right)$ of duration (h week ${ }^{-1}$ )

\begin{tabular}{|c|c|c|c|c|c|c|c|c|c|c|c|c|c|c|c|c|}
\hline \multirow[b]{3}{*}{ Country and centre } & \multicolumn{8}{|c|}{ Men } & \multicolumn{8}{|c|}{ Women } \\
\hline & \multirow[b]{2}{*}{$n^{\star}$} & \multicolumn{2}{|c|}{ Participation } & \multicolumn{5}{|c|}{$\begin{array}{c}\text { Duration } \\
\left(\text { h week }^{-1}\right)\end{array}$} & \multirow[b]{2}{*}{$n^{\star}$} & \multicolumn{2}{|c|}{ Participation } & \multicolumn{5}{|c|}{$\begin{array}{c}\text { Duration } \\
\left(\mathrm{h} \mathrm{week}^{-1}\right)\end{array}$} \\
\hline & & $n \dagger$ & $\%$ & Mean & SD & $P_{10}$ & $P_{50}$ & $P_{90}$ & & $n \dagger$ & $\%$ & Mean & SD & $P_{10}$ & $P_{50}$ & $P_{90}$ \\
\hline \multicolumn{17}{|l|}{ Greece } \\
\hline Greece & 3676 & 145 & 3.9 & 4.5 & 6.9 & 0.9 & 3.1 & 8.2 & 5993 & 131 & 2.2 & 3.7 & 3.2 & 1.0 & 2.9 & 7.0 \\
\hline \multicolumn{17}{|l|}{ Spain } \\
\hline Granada & 904 & 129 & 14.3 & 4.5 & 4.1 & 0.9 & 3.1 & 10.4 & 2597 & 53 & 2.0 & 2.8 & 3.6 & 0.6 & 1.6 & 4.9 \\
\hline Murcia & 1291 & 302 & 23.4 & 3.6 & 3.7 & 0.7 & 2.2 & 7.5 & 2331 & 208 & 8.9 & 3.2 & 3.3 & 0.6 & 2.1 & 6.9 \\
\hline Navarra & 1917 & 301 & 15.7 & 3.2 & 3.0 & 0.7 & 2.3 & 6.9 & 1745 & 218 & 12.5 & 2.8 & 3.0 & 0.6 & 2.1 & 5.8 \\
\hline San Sebastian & 2147 & 207 & 9.6 & 3.2 & 3.1 & 0.8 & 2.2 & 6.5 & 1639 & 73 & 4.5 & 2.3 & 2.3 & 0.6 & 1.6 & 4.9 \\
\hline Asturias & 1360 & 227 & 16.7 & 4.6 & 4.2 & 1.0 & 3.2 & 9.8 & 1962 & 133 & 6.8 & 3.0 & 2.6 & 0.9 & 2.1 & 7.0 \\
\hline \multicolumn{17}{|l|}{ Italy } \\
\hline Ragusa & 1064 & 401 & 37.7 & 1.9 & 2.2 & 0.3 & 1.0 & 4.4 & 940 & 123 & 13.1 & 1.5 & 1.7 & 0.2 & 0.8 & 3.8 \\
\hline Florence & 1702 & 955 & 56.1 & 2.6 & 3.1 & 0.3 & 1.4 & 6.6 & 6530 & 2122 & 32.5 & 2.6 & 2.8 & 0.3 & 1.6 & 6.4 \\
\hline Turin & 2774 & 1563 & 56.4 & 2.5 & 3.1 & 0.3 & 1.4 & 6.7 & 2307 & 600 & 26.0 & 1.7 & 2.1 & 0.2 & 0.8 & 3.8 \\
\hline Varese & 1585 & 1070 & 67.5 & 2.1 & 2.5 & 0.2 & 1.1 & 5.2 & 4470 & 2294 & 51.3 & 1.8 & 2.3 & 0.3 & 1.0 & 4.3 \\
\hline \multicolumn{17}{|l|}{ France } \\
\hline South coast $\ddagger$ & - & - & - & - & - & - & - & - & 5717 & 1158 & 20.3 & 3.0 & 5.4 & 0.5 & 1.4 & 6.9 \\
\hline South $\ddagger$ & - & - & - & - & - & - & - & - & 10124 & 2933 & 29.0 & 2.4 & 3.7 & 0.5 & 1.1 & 5.0 \\
\hline North-west $\ddagger$ & - & - & - & - & - & - & - & - & 6067 & 1997 & 32.9 & 2.5 & 3.9 & 0.5 & 1.1 & 5.1 \\
\hline North-east $\ddagger$ & - & - & - & - & - & - & - & - & 16736 & 4740 & 28.3 & 2.4 & 4.1 & 0.5 & 1.1 & 5.1 \\
\hline \multicolumn{17}{|l|}{ Germany } \\
\hline Heidelberg & 7235 & 5064 & 70.0 & 3.2 & 3.3 & 0.6 & 2.1 & 7.1 & 6442 & 4046 & 62.8 & 3.5 & 3.2 & 0.6 & 2.5 & 7.4 \\
\hline Potsdam & 6137 & 3315 & 54.0 & 3.4 & 3.4 & 0.6 & 2.3 & 7.3 & 7417 & 3845 & 51.8 & 3.6 & 3.4 & 0.6 & 2.6 & 7.6 \\
\hline \multicolumn{17}{|l|}{ The Netherlands } \\
\hline Bilthoven & 2510 & 1738 & 69.2 & 5.0 & 4.9 & 1.0 & 3.9 & 10.1 & 2669 & 1865 & 70.0 & 5.0 & 4.8 & 1.0 & 3.5 & 10.0 \\
\hline Utrechtł & - & - & - & - & - & - & - & - & 13384 & 11626 & 86.9 & 4.7 & 4.6 & 1.0 & 3.4 & 9.9 \\
\hline \multicolumn{17}{|l|}{ United Kingdom } \\
\hline General population & 6992 & 1687 & 24.1 & 3.0 & 4.3 & 0.6 & 1.8 & 6.2 & 9894 & 2324 & 23.5 & 3.0 & 4.1 & 0.6 & 1.9 & 6.1 \\
\hline 'Health-conscious' & 2476 & 783 & 31.6 & 3.1 & 3.5 & 0.6 & 1.9 & 7.2 & 8510 & 1765 & 20.7 & 2.8 & 3.3 & 0.6 & 1.9 & 6.0 \\
\hline \multicolumn{17}{|l|}{ Denmark } \\
\hline Copenhagen & 18477 & 12590 & 68.1 & 3.4 & 3.7 & 0.6 & 2.2 & 7.7 & 20856 & 15014 & 72.0 & 3.5 & 3.6 & 0.8 & 2.5 & 7.4 \\
\hline Aarhus & 8318 & 4829 & 58.1 & 2.6 & 2.8 & 0.6 & 1.7 & 5.7 & 8592 & 5582 & 64.9 & 3.7 & 2.7 & 0.6 & 1.9 & 5.6 \\
\hline \multicolumn{17}{|l|}{ Sweden } \\
\hline Malmö & 7288 & 3474 & 47.7 & 2.4 & 2.6 & 0.4 & 1.6 & 5.2 & 9325 & 4735 & 50.8 & 2.5 & 2.2 & 0.5 & 1.9 & 5.1 \\
\hline
\end{tabular}

${ }^{*}$ Number of respondents.

† Number of active participants.

$\ddagger$ Only women. 
Table 4 Gardening in men and women aged 50-64 years in different European Prospective Investigation into Cancer and Nutrition (EPIC) centres: participation $(n, \%)$ and age-adjusted mean, standard deviation (SD), and 10th, 50th and 90th percentiles $\left(P_{10}, P_{50}\right.$ and $\mathrm{P}_{90}$ ) of duration $\left(\mathrm{h} \mathrm{week}^{-1}\right)$

\begin{tabular}{|c|c|c|c|c|c|c|c|c|c|c|c|c|c|c|c|c|}
\hline \multirow[b]{3}{*}{ Country and centre } & \multicolumn{8}{|c|}{ Men } & \multicolumn{8}{|c|}{ Women } \\
\hline & \multirow[b]{2}{*}{$n^{*}$} & \multicolumn{2}{|c|}{ Participation } & \multicolumn{5}{|c|}{$\begin{array}{c}\text { Duration } \\
\left(\mathrm{h} \mathrm{week}^{-1}\right)\end{array}$} & \multirow[b]{2}{*}{$n^{*}$} & \multicolumn{2}{|c|}{ Participation } & \multicolumn{5}{|c|}{$\begin{array}{l}\text { Duration } \\
\left(\mathrm{h} \mathrm{week}^{-1}\right)\end{array}$} \\
\hline & & $n \dagger$ & $\%$ & Mean & SD & $P_{10}$ & $P_{50}$ & $\mathrm{P}_{90}$ & & $n \dagger$ & $\%$ & Mean & SD & $P_{10}$ & $P_{50}$ & $\mathrm{P}_{90}$ \\
\hline \multicolumn{17}{|l|}{ Greece } \\
\hline Greece & 3676 & 1856 & 50.5 & 7.0 & 6.6 & 1.2 & 4.8 & 15.0 & 5993 & 4113 & 68.6 & 6.4 & 5.3 & 1.3 & 5.0 & 13.9 \\
\hline \multicolumn{17}{|l|}{ Spain } \\
\hline Granada & 904 & 302 & 33.4 & 8.6 & 9.2 & 1.4 & 6.0 & 19.9 & 2597 & 649 & 25.0 & 3.5 & 3.3 & 1.0 & 2.5 & 6.9 \\
\hline Murcia & 1291 & 440 & 34.1 & 7.9 & 7.9 & 1.4 & 5.2 & 18.7 & 2331 & 442 & 19.0 & 3.1 & 3.7 & 0.6 & 2.0 & 6.9 \\
\hline Navarra & 1917 & 722 & 37.7 & 9.1 & 8.8 & 1.5 & 6.3 & 20.9 & 1745 & 406 & 23.3 & 3.5 & 4.4 & 0.7 & 2.2 & 7.2 \\
\hline San Sebastian & 2147 & 481 & 22.4 & 8.1 & 8.4 & 1.3 & 5.6 & 18.9 & 1639 & 228 & 13.9 & 4.8 & 5.2 & 0.8 & 3.1 & 11.7 \\
\hline Asturias & 1360 & 501 & 36.8 & 11.7 & 9.9 & 2.1 & 8.1 & 26.5 & 1962 & 502 & 25.6 & 7.9 & 7.8 & 1.1 & 4.8 & 20.2 \\
\hline \multicolumn{17}{|c|}{ 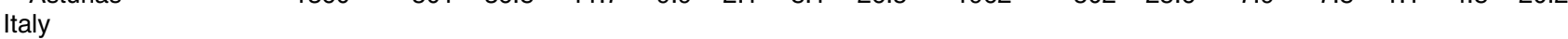 } \\
\hline Ragusa & 1064 & 705 & 66.3 & 5.4 & 5.1 & 0.8 & 3.5 & 15.7 & 940 & 445 & 47.3 & 2.5 & 2.6 & 0.5 & 1.6 & 5.6 \\
\hline Naplesł & - & - & - & - & - & - & - & - & 2306 & 298 & 12.9 & 2.1 & 3.0 & 0.2 & 1.1 & 5.6 \\
\hline Florence & 1702 & 868 & 51.0 & 4.5 & 4.6 & 0.3 & 2.8 & 12.0 & 6530 & 3141 & 48.1 & 2.3 & 2.5 & 0.3 & 1.4 & 5.2 \\
\hline Turin & 2774 & 1243 & 44.8 & 4.1 & 4.0 & 0.5 & 2.8 & 10.4 & 2307 & 908 & 39.4 & 2.3 & 2.5 & 0.3 & 1.4 & 5.9 \\
\hline Varese & 1585 & 1135 & 71.6 & 4.3 & 4.0 & 0.5 & 2.9 & 10.4 & 4470 & 2755 & 61.6 & 2.1 & 2.3 & 0.2 & 1.4 & 4.8 \\
\hline \multicolumn{17}{|l|}{ France } \\
\hline South coast $\ddagger$ & - & - & - & - & - & - & - & - & 5717 & 3822 & 66.9 & 4.0 & 4.9 & 0.7 & 2.4 & 8.6 \\
\hline South $\ddagger$ & - & - & - & - & - & - & - & - & 10124 & 7144 & 70.6 & 3.6 & 4.2 & 0.7 & 2.2 & 8.0 \\
\hline North-west‡ & - & - & - & - & - & - & - & - & 6067 & 4417 & 72.8 & 3.5 & 4.1 & 0.6 & 2.1 & 8.0 \\
\hline North-eastł & - & - & - & - & - & - & - & - & 16736 & 11001 & 65.7 & 3.4 & 4.2 & 0.6 & 2.1 & 7.6 \\
\hline \multicolumn{17}{|l|}{ Germany } \\
\hline Heidelberg & 7235 & 4962 & 68.6 & 4.2 & 5.3 & 0.5 & 2.5 & 9.8 & 6442 & 3903 & 60.6 & 3.2 & 3.5 & 0.5 & 2.1 & 7.3 \\
\hline Potsdam & 6137 & 4489 & 73.2 & 6.8 & 5.7 & 1.3 & 5.2 & 14.3 & 7417 & 4853 & 65.4 & 5.2 & 4.4 & 1.1 & 3.9 & 10.8 \\
\hline \multicolumn{17}{|l|}{ The Netherlands } \\
\hline Bilthoven & 2510 & 1549 & 61.7 & 3.7 & 4.1 & 0.6 & 2.4 & 8.1 & 2669 & 1411 & 52.9 & 2.8 & 3.0 & 0.6 & 1.9 & 5.7 \\
\hline Utrecht $\ddagger$ & - & - & - & - & - & - & - & - & 13384 & 9179 & 68.6 & 2.5 & 2.8 & 0.5 & 1.7 & 5.4 \\
\hline \multicolumn{17}{|l|}{ United Kingdom } \\
\hline General population & 6992 & 6197 & 88.6 & 5.4 & 6.0 & 0.8 & 3.7 & 11.8 & 9894 & 8081 & 81.7 & 4.5 & 4.8 & 0.8 & 3.0 & 10.0 \\
\hline 'Health-conscious' & 2476 & 2164 & 87.4 & 4.4 & 4.8 & 0.7 & 3.0 & 9.6 & 8510 & 7418 & 87.2 & 4.3 & 4.1 & 0.9 & 3.1 & 9.3 \\
\hline \multicolumn{17}{|l|}{ Denmark } \\
\hline Copenhagen & 18477 & 13840 & 74.9 & 3.3 & 3.5 & 0.6 & 2.4 & 6.9 & 20856 & 13400 & 64.3 & 2.8 & 2.8 & 0.6 & 2.0 & 5.9 \\
\hline Aarhus & 8318 & 7081 & 85.1 & 3.2 & 3.2 & 0.7 & 2.4 & 6.5 & 8592 & 6405 & 74.6 & 2.8 & 2.9 & 0.6 & 1.9 & 5.8 \\
\hline \multicolumn{17}{|l|}{ Sweden } \\
\hline Malmö & 7288 & 3797 & 52.1 & 2.5 & 3.0 & 0.4 & 1.9 & 5.5 & 9325 & 3790 & 40.6 & 2.4 & 2.6 & 0.3 & 1.7 & 5.3 \\
\hline
\end{tabular}

* Number of respondents.

† Number of active participants.

$\ddagger$ Only women.

Netherlands) and for women between zero (Naples, Italy) and $14.1 \mathrm{hweek}^{-1}$ (Bilthoven, The Netherlands). The proportion of subjects who did not participate in any recreational activities was less than $10 \%$ in all centres, except in the centres of Naples (Italy) and Malmö (Sweden).

Analysis of the difference in duration of total recreational activity between summer and winter seasons showed that, for all centres, time dedicated to recreational activity was higher in the summer than in winter. As shown in Table 7, the differences between summer and winter seasons were more pronounced for the centres from northern Europe than for the centres in southern Europe. The difference between summer- and wintertime was clearest for gardening. There was also a clear difference for duration of cycling between summertime and wintertime, especially in the centres from The Netherlands, Germany, Sweden and Denmark. For walking and for sports/exercise, only a small difference between summer and winter was observed in most centres (data not shown).

Table 8 shows participation in and time dedicated to household activities among men and women from the different EPIC centres. Almost all women performed household activities, while there were substantial variations in the proportions of men who performed household activities between centres. In the Spanish centres, about one-third of the men took part in housework, whereas in the centre of Malmö (Sweden), almost all men participated in household activities. In men of all centres, the median duration of household activities was less than $7 \mathrm{~h}^{-1} \mathrm{ek}^{-1}$. In women, time spent on household activities was the highest in the centres of the Mediterranean countries, with a median duration of 23-39 $\mathrm{hweek}^{-1}$. Among women from the British, German, Swedish and Dutch centres, the median duration of household activities was between 10 and $20 \mathrm{hweek}^{-1}$. The median duration of household activities was less than 
Table 5 Sports/exercise in men and women aged 50-64 years in different European Prospective Investigation into Cancer and Nutrition (EPIC) centres: participation ( $n, \%)$ and age-adjusted mean, standard deviation (SD), and 10th, 50th and 90th percentiles $\left(P_{10}, P_{50}\right.$ and $\mathrm{P}_{90}$ ) of duration $\left(\mathrm{h} \mathrm{week}^{-1}\right.$ )

\begin{tabular}{|c|c|c|c|c|c|c|c|c|c|c|c|c|c|c|c|c|}
\hline \multirow[b]{3}{*}{ Country and centre } & \multicolumn{8}{|c|}{ Men } & \multicolumn{8}{|c|}{ Women } \\
\hline & \multirow[b]{2}{*}{$n^{\star}$} & \multicolumn{2}{|c|}{ Participation } & \multicolumn{5}{|c|}{$\begin{array}{l}\text { Duration } \\
\left(\mathrm{h}^{\text {week }}{ }^{-1}\right)\end{array}$} & \multirow[b]{2}{*}{$n^{*}$} & \multicolumn{2}{|c|}{ Participation } & \multicolumn{5}{|c|}{$\begin{array}{c}\text { Duration } \\
\left(\mathrm{h}^{2} \text { week }^{-1}\right)\end{array}$} \\
\hline & & $n \dagger$ & $\%$ & Mean & SD & $P_{10}$ & $P_{50}$ & $P_{90}$ & & $n \dagger$ & $\%$ & Mean & SD & $P_{10}$ & $P_{50}$ & $P_{90}$ \\
\hline \multicolumn{17}{|l|}{ Greece } \\
\hline Greece & 3676 & 1061 & 28.9 & 2.2 & 2.4 & 0.5 & 1.1 & 5.0 & 5993 & 1373 & 22.9 & 2.5 & 2.4 & 0.5 & 1.5 & 5.0 \\
\hline \multicolumn{17}{|l|}{ Spain } \\
\hline Granada & 904 & 139 & 15.4 & 3.7 & 3.9 & 1.0 & 3.0 & 7.0 & 2597 & 370 & 14.3 & 2.7 & 3.0 & 1.0 & 2.0 & 5.0 \\
\hline Murcia & 1291 & 242 & 18.8 & 3.8 & 3.5 & 1.0 & 3.0 & 7.5 & 2331 & 288 & 12.4 & 2.8 & 4.0 & 1.0 & 2.0 & 5.0 \\
\hline Navarra & 1917 & 405 & 21.1 & 3.4 & 3.1 & 1.0 & 2.5 & 7.0 & 1745 & 348 & 19.9 & 2.5 & 2.4 & 1.0 & 2.0 & 5.0 \\
\hline San Sebastian & 2147 & 611 & 28.5 & 4.1 & 4.1 & 1.0 & 3.0 & 9.0 & 1639 & 454 & 27.7 & 3.8 & 3.6 & 1.0 & 3.0 & 7.0 \\
\hline Asturias & 1360 & 282 & 20.7 & 4.1 & 4.0 & 0.9 & 3.0 & 8.0 & 1962 & 332 & 16.9 & 2.9 & 2.4 & 1.0 & 3.0 & 6.0 \\
\hline \multicolumn{17}{|l|}{ Italy } \\
\hline Ragusa & 1064 & 265 & 24.9 & 2.1 & 2.4 & 0.3 & 1.5 & 4.8 & 940 & 224 & 23.8 & 1.8 & 2.0 & 0.5 & 1.5 & 3.7 \\
\hline Naples $\ddagger$ & - & - & - & - & - & - & - & - & 2306 & 167 & 7.2 & 1.8 & 1.2 & 0.5 & 1.5 & 3.5 \\
\hline Florence & 1702 & 840 & 19.4 & 2.9 & 3.0 & 0.5 & 1.6 & 6.5 & 6530 & 2673 & 40.9 & 2.2 & 2.2 & 0.5 & 1.5 & 4.8 \\
\hline Turin & 2774 & 1531 & 55.2 & 3.0 & 3.3 & 0.5 & 1.5 & 7.5 & 2307 & 1080 & 46.8 & 2.2 & 2.2 & 0.5 & 1.5 & 4.5 \\
\hline Varese & 1585 & 794 & 50.1 & 2.1 & 2.4 & 0.4 & 1.5 & 4.6 & 4470 & 1913 & 42.8 & 1.8 & 1.8 & 0.5 & 1.5 & 3.5 \\
\hline \multicolumn{17}{|l|}{ France } \\
\hline South coast & - & - & - & - & - & - & - & - & 5717 & 3582 & 62.7 & 3.6 & 4.8 & 1.0 & 2.0 & 7.5 \\
\hline South $\ddagger$ & - & - & - & - & - & - & - & - & 10124 & 5814 & 57.4 & 3.5 & 4.9 & 1.0 & 2.0 & 8.0 \\
\hline North-westł & - & - & - & - & - & - & - & - & 6067 & 3278 & 54.0 & 3.3 & 4.7 & 1.0 & 2.0 & 7.5 \\
\hline North-eastf & - & - & - & - & - & - & - & - & 16736 & 8925 & 53.3 & 3.6 & 5.2 & 1.0 & 2.0 & 8.0 \\
\hline \multicolumn{17}{|l|}{ Germany } \\
\hline Heidelberg & 7235 & 3598 & 49.7 & 3.2 & 2.8 & 1.0 & 2.4 & 6.4 & 6442 & 3488 & 54.1 & 2.6 & 2.5 & 1.0 & 2.0 & 5.0 \\
\hline Potsdam & 6137 & 1805 & 29.4 & 2.6 & 2.3 & 1.0 & 2.0 & 5.0 & 7417 & 2743 & 37.0 & 2.0 & 1.6 & 1.0 & 1.5 & 4.0 \\
\hline \multicolumn{17}{|l|}{ The Netherlands } \\
\hline Bilthoven & 2510 & 1128 & 44.9 & 3.3 & 3.4 & 1.0 & 2.0 & 7.0 & 2669 & 1373 & 51.4 & 2.6 & 3.1 & 1.0 & 2.0 & 5.0 \\
\hline Utrecht $\ddagger$ & - & - & - & - & - & - & - & - & 13384 & 7492 & 56.0 & 2.5 & 2.5 & 1.0 & 2.0 & 5.0 \\
\hline \multicolumn{17}{|l|}{ United Kingdom } \\
\hline General population & 6992 & 2584 & 37.0 & 3.3 & 3.4 & 0.9 & 2.0 & 7.0 & 9894 & 4353 & 44.0 & 2.9 & 3.6 & 1.0 & 2.0 & 6.0 \\
\hline 'Health-conscious' & 2476 & 1292 & 52.2 & 3.4 & 3.2 & 1.0 & 2.1 & 7.0 & 8510 & 5008 & 58.9 & 3.1 & 3.3 & 1.0 & 2.0 & 6.0 \\
\hline \multicolumn{17}{|l|}{ Denmark } \\
\hline Copenhagen & 18477 & 9146 & 49.5 & 2.9 & 2.6 & 0.9 & 2.0 & 6.0 & 20856 & 12127 & 58.2 & 2.2 & 2.0 & 0.5 & 1.5 & 4.5 \\
\hline Aarhus & 8318 & 3801 & 45.7 & 2.6 & 2.4 & 0.6 & 2.0 & 5.0 & 8592 & 4992 & 58.1 & 2.0 & 2.0 & 0.5 & 1.5 & 4.0 \\
\hline \multicolumn{17}{|l|}{ Sweden } \\
\hline Malmö & 7288 & 2981 & 40.9 & 2.6 & 2.8 & 0.5 & 1.7 & 6.0 & 9325 & 3688 & 39.6 & 2.1 & 2.3 & 0.5 & 1.5 & 5.0 \\
\hline
\end{tabular}

${ }^{*}$ Number of respondents.

† Number of active participants.

$\ddagger$ Only women.

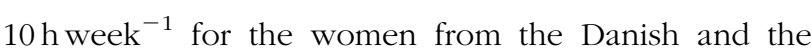
French centres.

The proportion of subjects who did home repair (do-ityourself) activities varied between EPIC centres from $11 \%$ (San Sebastian, Spain) to 89\% (Varese, Italy) in men and from $2 \%$ (Naples, Italy) to 66\% (Varese, Italy) in women (Table 9). Overall, the median duration of this activity was less than 1 hour daily in all centres. The proportion of women from the Spanish centres who did home repair was low compared with women from the other centres, although they spent the most time in this activity.

\section{Discussion}

This study describes the types of physical activity and the amount of time dedicated to these activities in the different EPIC centres. Professional activities were mainly sedentary or standing in almost all centres. A higher proportion of manual work was observed in participants from the centres of Greece, Umeå (Sweden) and Aarhus (Denmark), men from the Copenhagen (Denmark) centre and women from the Utrecht (The Netherlands) centre.

In men, the highest participation rates were found for walking, followed by gardening and home repair, and in women for household activities and walking. In most of the centres, participation in sports and cycling was lower than participation in other non-professional activities. Interesting deviations from this pattern were observed in some centres. In The Netherlands, cycling was more common than in most other centres, and in the French centres, the women participated in sports/exercise more frequently than women from the other centres.

Overall, the EPIC participants devoted only a limited time to their recreational activities. The median duration of activity was the highest $\left(15 \mathrm{hweek}^{-1}\right)$ in men from the centre of Bilthoven (The Netherlands), but in most centres 
EPIC physical activity

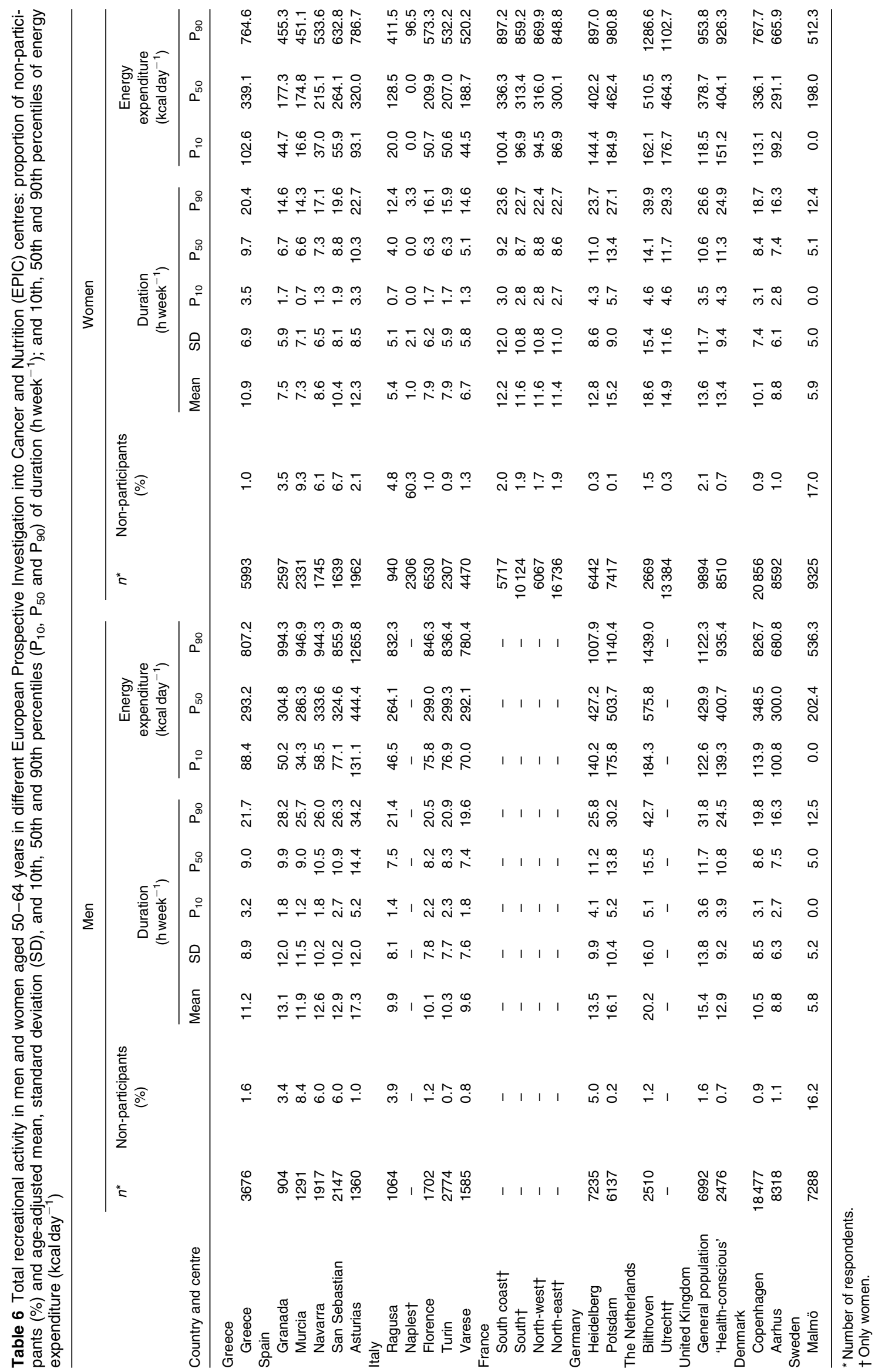


Table 7 Differences in duration of recreational activities between summer and winter ( $\mathrm{h} \mathrm{week}^{-1}$ ) in men and women aged 50-64 years in different European Prospective Investigation into Cancer and Nutrition (EPIC) centres: median, 95\% confidence interval

\begin{tabular}{|c|c|c|c|c|c|c|c|c|}
\hline \multirow[b]{3}{*}{ Country and centre } & \multirow[b]{3}{*}{$n^{*}$} & \multicolumn{3}{|c|}{ Men } & \multirow[b]{3}{*}{$n^{\star}$} & \multirow{2}{*}{\multicolumn{3}{|c|}{$\begin{array}{c}\text { Women } \\
\begin{array}{c}\text { Difference of duration }\left(\mathrm{h}_{\text {week }}{ }^{-1}\right) \\
\text { summer }- \text { winter }\end{array}\end{array}$}} \\
\hline & & \multicolumn{3}{|c|}{$\begin{array}{c}\text { Difference of duration }\left(\mathrm{h}_{\text {week }}{ }^{-1} \text { ) }\right. \\
\text { summer - winter }\end{array}$} & & & & \\
\hline & & Median & $\begin{array}{l}\text { Lower } \\
\text { confidence } \\
\text { limit }\end{array}$ & $\begin{array}{c}\text { Upper } \\
\text { confidence } \\
\text { limit }\end{array}$ & & Median & $\begin{array}{l}\text { Lower } \\
\text { confidence } \\
\quad \text { limit }\end{array}$ & $\begin{array}{l}\text { Upper } \\
\text { confidence } \\
\text { limit }\end{array}$ \\
\hline \multicolumn{9}{|l|}{ Greece } \\
\hline Greece & 3676 & 1.1 & 1.0 & 1.3 & 5993 & 1.7 & 1.2 & 1.8 \\
\hline \multicolumn{9}{|l|}{ Spain } \\
\hline Granada & 904 & 0.3 & 0.2 & 0.4 & 2597 & 0.1 & 0.0 & 0.1 \\
\hline Murcia & 1291 & 0.4 & 0.3 & 0.5 & 2331 & 0.0 & 0.0 & 0.1 \\
\hline Navarra & 1917 & 0.7 & 0.7 & 0.8 & 1745 & 0.1 & 0.0 & 0.1 \\
\hline San Sebastian & 2147 & 0.6 & 0.5 & 0.6 & 1639 & 0.1 & 0.1 & 0.1 \\
\hline Asturias & 1360 & 0.6 & 0.5 & 0.6 & 1962 & 0.1 & 0.1 & 0.2 \\
\hline \multicolumn{9}{|l|}{ Italy } \\
\hline Ragusa & 1064 & 2.0 & 1.7 & 2.3 & 940 & 1.0 & 0.6 & 1.2 \\
\hline Florence & 1702 & 2.6 & 2.4 & 2.6 & 6530 & 1.9 & 1.8 & 1.9 \\
\hline Turin & 2774 & 3.8 & 3.6 & 4.0 & 2307 & 2.1 & 2.0 & 2.1 \\
\hline Varese & 1585 & 4.4 & 4.1 & 4.8 & 4470 & 2.6 & 2.4 & 2.7 \\
\hline \multicolumn{9}{|l|}{ France } \\
\hline South coast $\dagger$ & - & - & - & - & 5717 & 2.2 & 2.1 & 2.2 \\
\hline South† & - & - & - & - & 10124 & 4.0 & 3.9 & 4.1 \\
\hline North-west† & - & - & - & - & 6067 & 4.0 & 3.9 & 4.1 \\
\hline North-east† & - & - & - & - & 16736 & 4.1 & 4.0 & 4.2 \\
\hline \multicolumn{9}{|l|}{ Germany } \\
\hline Heidelberg & 7235 & 4.6 & 4.4 & 4.8 & 6442 & 4.1 & 4.0 & 4.2 \\
\hline Potsdam & 6137 & 6.7 & 6.5 & 7.0 & 7417 & 6.1 & 6.0 & 6.2 \\
\hline \multicolumn{9}{|l|}{ The Netherlands } \\
\hline Bilthoven & 2510 & 5.5 & 5.0 & 5.7 & 2669 & 5.0 & 4.1 & 5.0 \\
\hline Utrecht† & - & - & - & - & 13384 & 5.0 & 4.9 & 5.1 \\
\hline \multicolumn{9}{|l|}{ United Kingdom } \\
\hline General population & 6992 & 5.2 & 5.1 & 5.4 & 9894 & 5.0 & 4.9 & 5.1 \\
\hline 'Health-conscious' & 2476 & 4.5 & 4.2 & 4.7 & 8510 & 5.1 & 5.1 & 5.2 \\
\hline \multicolumn{9}{|l|}{ Denmark } \\
\hline Copenhagen & 18477 & 3.9 & 3.9 & 4.0 & 20856 & 3.8 & 3.8 & 3.9 \\
\hline Aarhus & 8318 & 4.3 & 4.1 & 4.4 & 8592 & 4.0 & 3.9 & 4.1 \\
\hline \multicolumn{9}{|l|}{ Sweden } \\
\hline Malmö & 7288 & 0.7 & 0.7 & 0.8 & 9325 & 0.7 & 0.7 & 0.7 \\
\hline
\end{tabular}

${ }^{*}$ Number of respondents.

†Only women.

the duration was considerably lower. The variations in total time spent for recreational activities were mainly due to differences in time spent on walking and gardening. Cycling and sports were less common among participants from the southern European centres (Spain; Greece; Ragusa and Naples, Italy) compared with the central and northern European centres. A finding of a similar geographical distribution of recreational activity pattern was documented in a pan-European survey. In this study, physical activity and attitudes and beliefs about physical activity in the European Union were investigated ${ }^{17}$.

There was a clear difference in the duration of total recreational activity between summer and winter in almost all centres, which is consistent with common knowledge. Seasonal variation of recreational activity is clearly associated with environmental factors such as temperature and numbers of hours of daylight per day ${ }^{18}$. Unfavourable conditions for recreational activities are more pronounced in northern Europe than in southern Europe across the seasons. This is in accordance with our finding of more apparent summer vs. winter differences in recreational activity in centres from northern and middle Europe (except in Malmö, Sweden) than in centres from southern Europe. Furthermore, gardening contributed the most to the seasonal differences, compared with the other recreational activities, across EPIC centres. This activity is highly dependent on weather conditions.

The regional distribution of physical activity may clearly be influenced by cultural conditions ${ }^{19}$ and environmental factors. However, it can also be that the differences in responses to the core questions on physical activities in EPIC might partly be influenced by the local conditions. The EPIC questions were formulated in English and then translated into the local language. Therefore participants may have interpreted the questions differently in the various centres.

We are already aware of a number of limiting features of the data, mostly related to centre-specific differences. In 
Table 8 Household activity in men and women aged 50-64 years in different European Prospective Investigation into Cancer and Nutrition (EPIC) centres: participation $(n, \%)$ and age-adjusted mean, standard deviation (SD), and 10th, 50th and 90th percentiles $\left(P_{10}\right.$, $\mathrm{P}_{50}$ and $\mathrm{P}_{90}$ ) of duration (h week ${ }^{-1}$ )

\begin{tabular}{|c|c|c|c|c|c|c|c|c|c|c|c|c|c|c|c|c|}
\hline \multirow[b]{3}{*}{ Country and centre } & \multicolumn{8}{|c|}{ Men } & \multicolumn{8}{|c|}{ Women } \\
\hline & \multirow[b]{2}{*}{$n^{\star}$} & \multicolumn{2}{|c|}{ Participation } & \multicolumn{5}{|c|}{$\begin{array}{c}\text { Duration } \\
\left(\mathrm{h} \mathrm{week}^{-1}\right)\end{array}$} & \multirow[b]{2}{*}{$n^{\star}$} & \multicolumn{2}{|c|}{ Participation } & \multicolumn{5}{|c|}{$\begin{array}{c}\text { Duration } \\
\left(\mathrm{h} \mathrm{week}^{-1}\right)\end{array}$} \\
\hline & & $n \dagger$ & $\%$ & Mean & SD & $P_{10}$ & $P_{50}$ & $P_{90}$ & & $n \dagger$ & $\%$ & Mean & SD & $\mathrm{P}_{10}$ & $\mathrm{P}_{50}$ & $P_{90}$ \\
\hline \multicolumn{17}{|l|}{ Greece } \\
\hline Greece & 3676 & 2039 & 55.5 & 5.8 & 5.7 & 1.3 & 3.5 & 13.9 & 5993 & 5906 & 98.6 & 29.7 & 12.0 & 14.8 & 28.6 & 42.5 \\
\hline \multicolumn{17}{|l|}{ Spain } \\
\hline Granada & 904 & 239 & 26.4 & 6.0 & 6.4 & 0.9 & 3.7 & 14.1 & 2597 & 2584 & 99.5 & 37.3 & 14.2 & 19.9 & 35.5 & 56.0 \\
\hline Murcia & 1291 & 319 & 24.7 & 6.8 & 6.8 & 1.4 & 4.2 & 14.3 & 2331 & 2293 & 98.4 & 36.3 & 16.3 & 14.5 & 35.3 & 56.4 \\
\hline Navarra & 1917 & 521 & 27.2 & 6.2 & 6.7 & 1.1 & 4.1 & 14.0 & 1745 & 1727 & 99.0 & 37.4 & 16.0 & 14.2 & 39.3 & 56.5 \\
\hline San Sebastian & 2147 & 708 & 33.0 & 7.2 & 7.0 & 1.4 & 5.2 & 14.4 & 1639 & 1605 & 97.9 & 34.9 & 17.2 & 13.1 & 35.0 & 56.5 \\
\hline Asturias & 1360 & 412 & 30.3 & 7.3 & 7.2 & 1.4 & 5.5 & 14.4 & 1962 & 1924 & 98.1 & 31.8 & 13.4 & 13.9 & 34.5 & 49.1 \\
\hline \multicolumn{17}{|l|}{ Italy } \\
\hline Ragusał & - & - & - & - & - & - & - & - & 940 & 940 & 100.0 & 33.2 & 15.8 & 10.9 & 37.5 & 56.4 \\
\hline Naples $\ddagger$ & - & - & - & - & - & - & - & - & 2306 & 2304 & 99.9 & 25.6 & 21.1 & 3.2 & 23.5 & 56.4 \\
\hline Florenceł & - & - & - & - & - & - & - & - & 6530 & 6508 & 99.7 & 28.3 & 15.7 & 10.2 & 23.9 & 55.7 \\
\hline Turin $\ddagger$ & - & - & - & - & - & - & - & - & 2307 & 2296 & 99.5 & 27.9 & 15.4 & 10.2 & 23.8 & 55.7 \\
\hline Varese & - & - & - & - & - & - & - & - & 4470 & 4442 & 99.4 & 31.4 & 15.4 & 10.8 & 24.3 & 56.0 \\
\hline \multicolumn{17}{|c|}{ - } \\
\hline South coast $\ddagger$ & - & - & - & - & - & - & - & - & 5717 & 5441 & 95.2 & 6.5 & 4.2 & 2.5 & 4.5 & 13.0 \\
\hline South $\ddagger$ & - & - & - & - & - & - & - & - & 10124 & 9594 & 94.8 & 6.3 & 4.1 & 2.8 & 4.4 & 12.8 \\
\hline North-westł & - & - & - & - & - & - & - & - & 6067 & 5767 & 95.1 & 6.1 & 4.0 & 2.8 & 4.3 & 12.5 \\
\hline North-east‡ & - & - & - & - & - & - & - & - & 16736 & 15359 & 91.8 & 6.1 & 4.1 & 2.7 & 4.3 & 12.7 \\
\hline \multicolumn{17}{|l|}{ Germany } \\
\hline Heidelberg & 7235 & 5023 & 69.4 & 5.2 & 5.4 & 1.0 & 3.3 & 11.8 & 6442 & 6396 & 99.3 & 20.0 & 12.5 & 5.8 & 18.9 & 35.5 \\
\hline Potsdam & 6137 & 4985 & 81.2 & 6.1 & 5.8 & 1.3 & 4.3 & 13.9 & 7417 & 7380 & 99.5 & 15.5 & 9.0 & 5.4 & 13.9 & 27.9 \\
\hline \multicolumn{17}{|l|}{ The Netherlands } \\
\hline Bilthoven & 2510 & 1728 & 68.8 & 6.5 & 6.8 & 1.2 & 4.4 & 14.2 & 2669 & 2637 & 98.8 & 21.3 & 14.1 & 5.9 & 19.7 & 40.2 \\
\hline Utrecht‡ & - & - & - & - & - & - & - & - & 13384 & 13322 & 99.5 & 19.3 & 11.4 & 5.9 & 17.5 & 35.7 \\
\hline \multicolumn{17}{|l|}{ United Kingdom } \\
\hline General population & 6992 & 3797 & 54.3 & 5.5 & 6.3 & 1.1 & 3.5 & 11.8 & 9894 & 9356 & 94.6 & 20.1 & 14.4 & 5.1 & 16.8 & 39.4 \\
\hline 'Health-conscious' & 2476 & 2045 & 82.6 & 6.4 & 6.1 & 1.2 & 4.4 & 14.1 & 8510 & 8292 & 97.4 & 16.7 & 12.4 & 4.2 & 14.0 & 30.8 \\
\hline \multicolumn{17}{|l|}{ Denmark } \\
\hline Copenhagen & 18477 & 16229 & 87.8 & 3.6 & 3.4 & 1.0 & 2.5 & 7.4 & 20856 & 20652 & 99.0 & 7.2 & 6.1 & 2.0 & 5.3 & 14.5 \\
\hline Aarhus & 8318 & 6945 & 83.5 & 3.2 & 3.0 & 0.9 & 2.3 & 6.4 & 8592 & 8530 & 99.3 & 8.2 & 6.8 & 2.4 & 6.1 & 16.8 \\
\hline \multicolumn{17}{|l|}{ Sweden } \\
\hline Malmö & 7288 & 6818 & 93.6 & 6.8 & 4.8 & 1.7 & 5.4 & 14.3 & 9325 & 9111 & 97.7 & 17.3 & 9.5 & 6.4 & 15.6 & 29.9 \\
\hline
\end{tabular}

* Number of respondents.

† Number of active participants.

$\ddagger$ Only women.

the centres from Spain, at present, work activity data do not distinguish between working and non-working participants. Therefore, professional activity described for these centres is not directly comparable with this activity in the remaining centres. In Spain, participants were asked about their main work-like activity, which corresponds to the main activity of the day rather than to work activity. For most individuals, however, the main activity of the day is consistent with work activity. Nevertheless, a much higher proportion of women from Spain reported a standing work activity compared with women from the other centres. This is probably due to classification of subjects who mainly did housekeeping activities as having a standing work activity. For men in the Spanish centres, the reported type of activity is more likely to be in agreement with work activity.

In Malmö, the recreational physical activity data were solicited through a different mode and subsequently re-coded into the four EPIC recreational activity categories: sports, cycling, walking and gardening. On the whole, the comparability of the EPIC questions and the Malmö questions is not yet known. The comparability of both questions will be tested in a sample of the EPIC Malmö cohort during follow-up in the future. The present analysis showed that participation in and duration of most recreational activities were relatively low in the Malmö centre compared with other centres from northern Europe such as the Danish centres. These differences may represent differences in activity level between Malmö and the other centres, but may also represent differences due to the application of a different mode of inquiry.

Also, in Naples (Italy), questions other than the core EPIC questions were used to assess non-professional activity. Participation in and time dedicated to recreational activity were much lower for Naples than for all other centres. This may be due to differences between centres as 
Table 9 Home repair (do-it-yourself) activity in men and women aged 50-64 years in different European Prospective Investigation into Cancer and Nutrition (EPIC) centres: participation ( $n, \%)$ and age-adjusted mean, standard deviation (SD), and 10th, 50th and 90th percentiles $\left(P_{10}, P_{50}\right.$ and $\left.P_{90}\right)$ of duration (hweek ${ }^{-1}$ )

\begin{tabular}{|c|c|c|c|c|c|c|c|c|c|c|c|c|c|c|c|c|}
\hline \multirow[b]{3}{*}{ Country and centre } & \multicolumn{8}{|c|}{ Men } & \multicolumn{8}{|c|}{ Women } \\
\hline & \multirow[b]{2}{*}{$n^{\star}$} & \multicolumn{2}{|c|}{ Participation } & \multicolumn{5}{|c|}{$\begin{array}{l}\text { Duration } \\
\left(\mathrm{h} \mathrm{week}^{-1}\right)\end{array}$} & \multirow[b]{2}{*}{$n^{\star}$} & \multicolumn{2}{|c|}{ Participation } & \multicolumn{5}{|c|}{$\begin{array}{c}\text { Duration } \\
\left(\mathrm{h} \text { week }^{-1}\right)\end{array}$} \\
\hline & & $n \dagger$ & $\%$ & Mean & SD & $P_{10}$ & $P_{50}$ & $P_{90}$ & & $n \dagger$ & $\%$ & Mean & SD & $P_{10}$ & $P_{50}$ & $\mathrm{P}_{90}$ \\
\hline \multicolumn{17}{|l|}{ Greece } \\
\hline Greece & 3676 & 755 & 20.5 & 3.9 & 4.1 & 1.0 & 2.5 & 8.4 & 5993 & 281 & 4.7 & 2.5 & 2.8 & 0.7 & 1.7 & 5.2 \\
\hline \multicolumn{17}{|l|}{ Spain } \\
\hline Granada & 904 & 119 & 13.2 & 6.4 & 8.5 & 1.0 & 3.5 & 14.6 & 2597 & 159 & 6.1 & 5.5 & 8.0 & 1.0 & 2.8 & 13.4 \\
\hline Murcia & 1291 & 208 & 16.1 & 6.7 & 9.4 & 1.0 & 2.8 & 15.2 & 2331 & 73 & 3.1 & 6.9 & 10.4 & 1.1 & 3.3 & 20.4 \\
\hline Navarra & 1917 & 299 & 15.6 & 4.9 & 6.6 & 0.8 & 2.6 & 10.7 & 1745 & 255 & 14.6 & 10.1 & 10.2 & 1.4 & 6.6 & 21.5 \\
\hline San Sebastian & 2147 & 237 & 11.0 & 5.5 & 7.2 & 1.1 & 2.6 & 14.0 & 1639 & 59 & 3.6 & 6.3 & 8.6 & 1.3 & 3.5 & 14.6 \\
\hline Asturias & 1360 & 248 & 18.2 & 7.4 & 9.4 & 0.9 & 3.6 & 19.4 & 1962 & 48 & 2.5 & 6.7 & 9.2 & 0.8 & 2.8 & 21.3 \\
\hline \multicolumn{17}{|l|}{ Italy } \\
\hline Ragusa & 1064 & 689 & 64.8 & 2.9 & 4.2 & 0.2 & 1.4 & 7.8 & 940 & 557 & 59.3 & 4.7 & 4.8 & 0.6 & 2.9 & 14.9 \\
\hline Naplesł & - & - & - & - & - & - & - & - & 2306 & 56 & 2.4 & 2.2 & 4.1 & 0.1 & 0.8 & 5.5 \\
\hline Florence & 1702 & 1453 & 85.4 & 3.4 & 4.5 & 0.3 & 1.8 & 8.6 & 6530 & 4231 & 64.8 & 2.8 & 3.3 & 0.4 & 1.6 & 7.1 \\
\hline Turin & 2774 & 2421 & 87.3 & 3.8 & 4.7 & 0.5 & 2.0 & 9.4 & 2307 & 1453 & 63.0 & 3.1 & 3.6 & 0.4 & 1.6 & 7.6 \\
\hline Varese & 1585 & 1417 & 89.4 & 4.4 & 5.4 & 0.4 & 2.1 & 17.3 & 4470 & 2970 & 66.4 & 3.0 & 3.7 & 0.4 & 1.6 & 7.7 \\
\hline \multicolumn{17}{|l|}{ France } \\
\hline South coast & - & - & - & - & - & - & - & - & 5717 & 2817 & 49.3 & 4.0 & 5.3 & 0.9 & 2.4 & 9.1 \\
\hline South $\ddagger$ & - & - & - & - & - & - & - & - & 10124 & 5257 & 51.9 & 4.1 & 5.4 & 0.9 & 2.4 & 9.1 \\
\hline North-westł & - & - & - & - & - & - & - & - & 6067 & 3205 & 52.8 & 4.3 & 5.6 & 0.9 & 2.4 & 10.1 \\
\hline North-east $\ddagger$ & - & - & - & - & - & - & - & - & 16736 & 8507 & 50.8 & 4.4 & 5.8 & 0.9 & 2.4 & 10.0 \\
\hline \multicolumn{17}{|l|}{ Germany } \\
\hline Heidelberg & 7235 & 4696 & 64.9 & 4.8 & 6.8 & 0.8 & 2.4 & 10.7 & 6442 & 1279 & 19.9 & 3.1 & 5.4 & 0.6 & 1.5 & 6.2 \\
\hline Potsdam & 6137 & 3675 & 64.8 & 6.4 & 7.8 & 1.0 & 3.4 & 15.2 & 7417 & 1009 & 13.6 & 3.5 & 5.4 & 0.7 & 1.7 & 7.4 \\
\hline \multicolumn{17}{|l|}{ The Netherlands } \\
\hline Bilthoven & 2510 & 1746 & 69.6 & 6.4 & 6.9 & 1.2 & 3.9 & 14.8 & 2669 & 642 & 24.1 & 4.4 & 5.6 & 1.0 & 2.4 & 10.2 \\
\hline Utrecht $\ddagger$ & . & - & - & . & - & - & - & - & 13384 & 3900 & 29.1 & 3.8 & 4.7 & 0.9 & 2.3 & 8.5 \\
\hline \multicolumn{17}{|l|}{ United Kingdom } \\
\hline General population & 6992 & 4919 & 70.4 & 5.2 & 6.4 & 0.9 & 2.8 & 10.7 & 9894 & 2073 & 21.0 & 4.7 & 7.4 & 0.8 & 2.2 & 10.4 \\
\hline 'Health-conscious' & 2476 & 1913 & 77.3 & 4.6 & 5.8 & 0.8 & 2.6 & 10.5 & 8510 & 3470 & 40.8 & 3.7 & 5.0 & 0.8 & 2.1 & 8.4 \\
\hline \multicolumn{17}{|l|}{ Denmark } \\
\hline Copenhagen & 18477 & 15512 & 84.0 & 3.7 & 4.3 & 0.8 & 2.4 & 8.2 & 20856 & 8766 & 42.0 & 2.3 & 2.8 & 0.6 & 1.4 & 4.6 \\
\hline Aarhus & 8318 & 7181 & 86.3 & 3.6 & 4.2 & 0.9 & 2.4 & 7.7 & 8592 & 3625 & 42.2 & 2.2 & 2.8 & 0.6 & 1.4 & 4.3 \\
\hline
\end{tabular}

* Number of respondents.

$\dagger$ Number of active participants.

‡Only women.

well as to the use of different questions. The comparability of the physical activity questions used in the EPIC Naples centre and the EPIC physical activity questions has not yet been studied.

This study was not intended to show differences in energy expenditure across centres or to rank subjects and centres based on their activity level. Calculation of total time dedicated to physical activities is a different concept to the energy cost of activities. Nevertheless, Table 6 shows, alongside information on total duration of activities, estimates of energy expenditure calculated using the energy cost coefficients of schofield and James $^{20}$. It illustrates a discrepancy between rankings of the centres based on duration of activity and energy expenditure.

In EPIC, the information on intensity of nonprofessional physical activity is limited. Analysis based on duration of non-professional activity with a moderateto-high intensity such as sports and cycling showed a low participation in these activities among participants from the Greek and Spanish centres and from Ragusa and Naples (Italy). Intensity of physical activity was also solicited in EPIC by inquiring about duration of nonprofessional activities done vigorously enough to cause sweating and/or a faster heart beat (Appendix A). We did not present the results here because we felt that this variable may be confounded with other factors such as temperature $^{21}$. In addition, subjects with a low degree of fitness may experience sweating and/or a faster heart beat earlier than fitter individuals.

A further limitation of our analysis was the restriction to the age group of 50-64 years. This group is relatively heterogeneous with respect to time dedicated to any kind of physical activity, since it involves both subjects who still have a profession and those who are retired. Non-workers have quite different activity patterns from employed subjects. Employed workers dedicate less time to recreational activities, sports and gardening, and household activities (data not shown). Physical activity of the younger age groups may also be of interest, since a 
different effect of physical activity on breast cancer risk has been observed in premenopausal women compared with postmenopausal women?

Although the comparability of the physical activity data may be restricted, the EPIC study does enable description of the variation of a number of different types of activities, covering the main activities during the day and differences in duration of recreational physical activity, for a large number of subjects from various study populations across Europe. This may be of interest for other study groups. However, since the EPIC study populations were not intended to be representative of geographical regions, generalisation of the results of our analysis in terms of regional differences in physical activity are not appropriate, and the current analysis should be considered primarily as the description of activity patterns in the EPIC study centres.

\section{Acknowledgements}

The work described in this paper was carried out with financial support of the 'Europe Against Cancer Programme' of the European Commission (SANCO); Ligue contre le Cancer (France); Société 3M (France); Mutuelle Générale de l'Education Nationale; Institut National de la Santé et de la Recherche Médicale (INSERM); Institute Gustave Roussy; German Cancer Aid; German Cancer Research Centre; German Federal Ministry of Education and Research; Danish Cancer Society; Health Research Fund (FIS) of the Spanish Ministry of Health; the Spanish Regional Governments of Andalucia, Asturias, Basque Country, Murcia and Navarra; Cancer Research UK; Medical Research Council, UK; Stroke Association, UK; British Heart Foundation; Department of Health, UK; Food Standards Agency, UK; Wellcome Trust, UK; Greek Ministry of Health; Greek Ministry of Education; Italian Association for Research on Cancer; Italian National Research Council; Dutch Ministry of Public Health, Welfare and Sports; Dutch Prevention Funds; LK Research Funds; Dutch ZON (Zorg Onderzoek Nederland); World Cancer Research Fund; Swedish Cancer Society; Swedish Scientific Council; Regional Government of Skane, Sweden; Norwegian Cancer Society; Norwegian Research Council. Partial support for the publication of this supplement was provided by the Centre de Recherche et d'Information Nutritionnelles (CERIN).

In addition, we wish to thank all study participants for their co-operation and all interviewers who participated in the fieldwork studies in each EPIC centre.

\section{References}

1 US Department of Health and Human Services, Centers for Disease Control and Prevention, National Center for Chronic Disease Prevention and Health Promotion, The President's Council of Sports and Physical Fitness. Physical Activity and
Health: A Report of the Surgeon General. Washington, DC: Office of the Surgeon General, 1996.

2 Friedenreich CM. Physical activity and cancer prevention: from observational to intervention research. Cancer Epidemiol. Biomark. Prev. 2001; 10: 287-301.

3 Vainio H, Bianchini F, Cheney J. IARC Handbook of Cancer Prevention. Vol. 6. Weight Control and Physical Activity. Lyon: IARC Press, 2002.

4 Colbert LH, Hartman TJ, Malila N, Limburg PJ, Pietinen P, Virtamo J, et al. Physical activity in relation to cancer of the colon and rectum in a cohort of male smokers. Cancer Epidemiol. Biomark. Prev. 2001; 10: 265-8.

5 Shoff SM, Newcomb PA, Trentham-Dietz A, Remington PL, Mittendorf M, Greenberg ER, et al. Early-life physical activity and postmenopausal breast cancer: effect of body size and weight change. Cancer Epidemiol. Biomark. Prev. 2000; 9: $591-5$.

6 Verloop J, Rookus MA, van der Kooy K, van Leeuwen FE. Physical activity and breast cancer risk in women aged 2054 years. J. Natl. Cancer Inst. 2000; 92: 128-35.

7 Friedenreich CM, Thune I, Brinton LA, Albanes D. Epidemiologic issues related to the association between physical activity and breast cancer. Cancer 1998; 89(Suppl. 3): $600-10$.

8 Gammon MD, John EM, Britton JA. Recreational and occupational physical activities and risk of breast cancer. J. Natl. Cancer Inst. 1998; 90: 100-17.

9 Thune I, Brenn T, Lund E, Gaard M. Physical activity and the risk of breast cancer. N. Engl. J. Med. 1997; 336: 1269-75.

10 Lee I-M, Sesso HD, Paffenberger RS. Physical activity and risk of lung cancer. Int. J. Epidemiol. 1999; 28: 620-5.

11 Clarke G, Whittemore AS. Prostate cancer risk in relation to anthropometry and physical activity: The National Health and Nutrition Examination Survey I. Epidemiological Follow-Up Study. Cancer Epidemiol. Biomark. Prev. 2000; 9: 875-81.

12 Liu S, Lee I-M, Linson P, Ajani U, Buring JE, Hennekens CH. A prospective study of physical activity and risk of prostate cancer in US physicians. Int. J. Epidemiol. 2000; 29: 29-35.

13 Riboli E, Kaaks R. The EPIC Project: rationale and study design. European Prospective Investigation into Cancer and Nutrition. Int. J. Epidemiol. 1997; 26(Suppl. 1): S6-14.

14 Riboli E, Hunt KJ, Slimani N, Ferrari P, Norat T, Fahey M, et al. European Prospective Investigation into Cancer and Nutrition (EPIC) study: study populations and data collection. Public Health Nutr. 2002; 5(6B): 1113-24.

15 Pols MA, Peeters PHM, Ocké MC, Slimani N, Bueno-deMesquita HB, Collette HJA. Estimation of reproducibility and relative validity of the questions included in the EPIC physical activity questionnaire. Int. J. Epidemiol. 1997; 26(Suppl. 1): S181-9.

16 Slimani N, Kaaks R, Ferrari P, Casagrande C, Clavel-Chapelon F, Lotze $G$, et al. European Prospective Investigation into Cancer and Nutrition (EPIC) calibration study: rationale, design and population characteristics. Public Health Nutr. 2002; 5(6B): 1125-45.

17 Vaz de Almeida MD, Gracia P, Aonso C, D'Amicis A, Lappalainen R, Damkjaer S. Physical activity levels and body weight in a nationally representative sample in the European Union. Public Health Nutr. 1999; 2: 105-13.

18 Matthews CE, Freedson PS, Hebert JR, Stanek EJ III, Merriam $\mathrm{PA}$, Rosal MC, et al. Seasonal variation in household, occupational, and leisure time physical activity: longitudinal analyses from the seasonal variation of blood cholesterol study. Am. J. Epidemiol. 2001; 153: 172-83.

19 Kafatos A, Manios Y, Markatji I, Giachetti I, Vaz de Almeida MD, Engstrom LM. Regional, demographic and national influences on attitudes and beliefs with regard to physical activity, body weight and health in a nationally representative 
sample of the European Union. Public Health Nutr. 1999; 2 : $87-95$.

20 James WPT, Schofield EC. Human Energy Requirements: $A$ Manual for Planners and Nutritionists. Oxford/New York/Tokyo: Oxford University Press, 1990.

21 Domínguez-Berión F, Borrell C, Nebot M, Plasència A. Physical activity assessment in population surveys: can it really be simplified? Int. J. Epidemiol. 1999; 28: 53-7.

\section{Appendix A - EPIC physical activity questions}

1. Work

We would like to know the type and amount of physical activity involved in your work. Please check what best corresponds with your present occupation from the following four possibilities:

- Sedentary occupation

You spend most of your time sitting (such as in an office)

- Standing occupation

You spend most of your time standing and walking. However, your work does not require intense physical effort (e.g. shop assistant, hairdresser, guard, etc.)

- Manual work

This involves some physical effort including handling of heavy objects and use of tools (e.g. plumber, electrician, carpenter, etc.)

- Heavy manual work

This implies very vigorous physical activity including handling of very heavy objects (e.g. docker, miner, bricklayer, construction worker, etc.)

2. In a typical week during the past year, how many hours did you spend per week on each of the following activities:
- walking, including walking to work, shopping and leisure time

in summer __ hours per week

in winter _ hours per week

- cycling, including cycling to work, shopping and leisure time

in summer __ hours per week

in winter _ hours per week

- gardening

in summer __ hours per week

in winter __ hours per week

- do-it-yourself activities at home hours per week

- physical exercise such as fitness, aerobics, swimming, jogging, tennis, etc.

in summer _ hours per week in winter__ hours per week

- housework, such as cleaning, washing, cooking, child care, etc.

hours per week

3. In a typical week during the past year, did you engage in any of these activities vigorously enough to cause sweating or faster heart beat?

No Yes

- If yes, for how many hours per week in total did you perform vigorous activity? hours per week

4. In a typical week during the past year, how many flights of stairs did you climb per day?

floors per day 


\section{Appendix B - Malmö physical activity questions}

Physical activity during leisure time and transportation between workplace and home

The question concerns both activities during leisure time and the way you transport yourself between workplace and home, but not activities during working hours.

Specify in the table below how many minutes per week you spend (on average) per week at different activities during different seasons. If any activity is missing you can add it at the end of the table.

\begin{tabular}{|c|c|c|c|c|}
\hline Activities & Spring & Summer & Autumn & Winter \\
\hline \multicolumn{5}{|l|}{ Racket ball (minutes/week) } \\
\hline \multicolumn{5}{|l|}{ Table tennis (minutes/week) } \\
\hline \multicolumn{5}{|l|}{ Football/Handball (minutes/week) } \\
\hline \multicolumn{5}{|l|}{ Golf (minutes/week) } \\
\hline \multicolumn{5}{|l|}{ Jogging/Running (minutes/week) } \\
\hline \multicolumn{5}{|l|}{ Aerobics/Gymnastics (minutes/week) } \\
\hline \multicolumn{5}{|l|}{ Orienteering (minutes/week) } \\
\hline \multicolumn{5}{|l|}{ Swimming (minutes/week) } \\
\hline \multicolumn{5}{|l|}{ Tennis (minutes/week) } \\
\hline \multicolumn{5}{|l|}{ Cycling (minutes/week) } \\
\hline \multicolumn{5}{|l|}{ Walking (minutes/week) } \\
\hline \multicolumn{5}{|l|}{ Climbing stairs (minutes/week) } \\
\hline \multicolumn{5}{|l|}{ Folk dancing (minutes/week) } \\
\hline \multicolumn{5}{|l|}{ Ballroom dancing (minutes/week) } \\
\hline \multicolumn{5}{|l|}{ Grass cutting (minutes/week) } \\
\hline \multicolumn{5}{|l|}{ Digging (minutes/week) } \\
\hline \multicolumn{5}{|l|}{ Gardening (minutes/week) } \\
\hline (minutes/week) & & & & \\
\hline
\end{tabular}

